\title{
A Curriculum Development Process Model
}

Donald Dawley (E-mail: dawleydl@ muohio.edu), Miami University

Douglas Havelka (E-mail: havelkdj@ muohio.edu), Miami University

\begin{abstract}
An adaptive and systematic framework or methodology is needed to facilitate the development of the anticipative curriculum. To that end, some guiding principles and processes are suggested that can be used to address the MIS professional curricula as well as curricula for the business professional.
\end{abstract}

\section{Introduction}

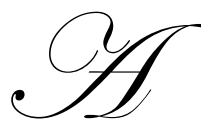

major role of MIS programs is to prepare Information Technology (IT) professionals for operational and management positions in societies characterized by multiple cultures, accelerating change in technology and the globalization of business. MIS programs must not only adapt to these changes, but must anticipate future changes in order to meet the needs of their constituents in a systematic, competitive and economic manner. Outsourcing (on and off-shore) mitigates to make this a global necessity rather than an institutional or national necessity.

Curricula therefore must be dynamic and more fluid in nature to be responsive to these changes in societies and technologies. Curricula should be forward looking since a major objective is to prepare students for future employment. Curricula must prepare students to work with current technologies, integrate new technologies and evaluate and apply emerging technologies over time (IS 2002 Model Curriculum; Hoffman, August 25 2003; Technology Review 2003). An adaptive and systematic framework or methodology is needed to facilitate the development of the anticipative curriculum. To that end, some guiding principles and processes are suggested that can be used to address the MIS professional curricula as well as curricula for the business professional.

Table 1: Design Guidelines For Curriculum MIS Development

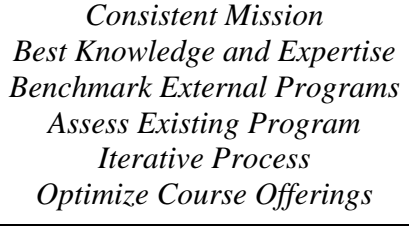

\section{Design Guidelines}

Table 1 presents the design guidelines that are suggested to ensure that the process meets its defined objectives efficiently and effectively. The first guideline, Consistent Mission, addresses the local environment in which the curriculum development process is taking place. The MIS mission must be consistent with the university and school of business missions. Therefore, it is important that prior to beginning the process that the university and school's mission statements be reviewed by the key players in the development process. Where potential conflicts or vague goals are present, inquiries should be made to attempt to resolve these issues.

The second guideline, Best Knowledge and Expertise, addresses the resources that are available for the development process. The process should objectively capitalize the best available knowledge and expertise from all possible sources. Professional expertise of constituent parties/stakeholders should be tapped to provide the best 
information possible. This may include faculty from the school, outside the school, outside the university, guidelines or other publications from respected sources such as professional associations or certification organizations, students, potential employers and advisory boards, and university administrators. This guideline should also lead to the identification of current and future trends in information technology and the best practices in the context of current and emerging IT. Diagram 1 is presented to display this input graphically.

Diagram 1: Constituent Parties And Stakeholders To Curriculum Development

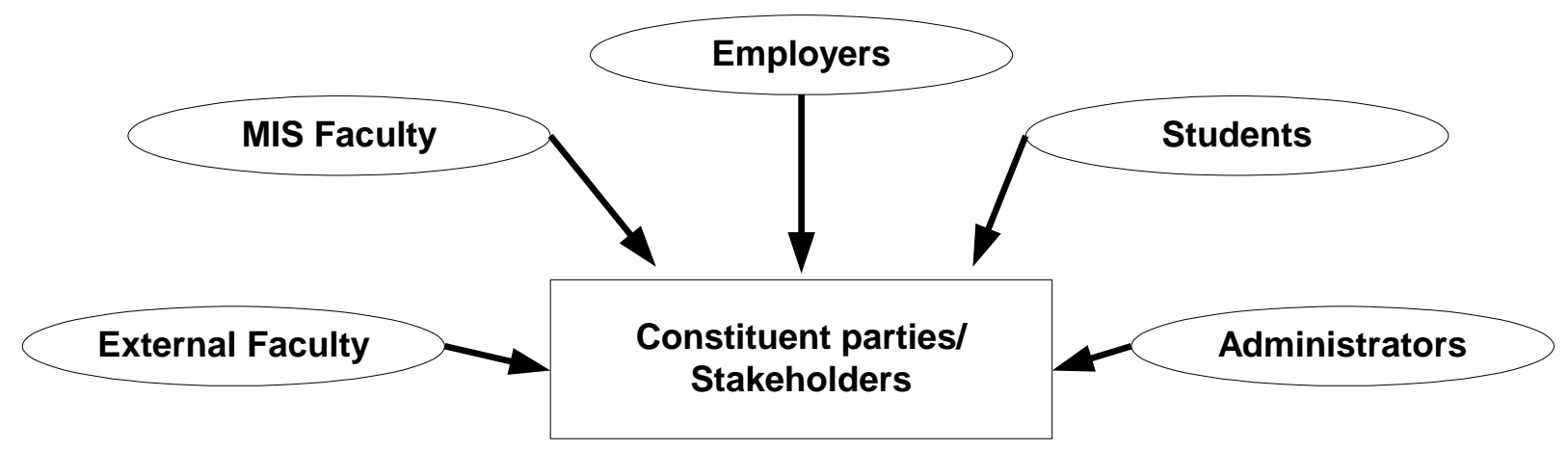

The third guideline, Benchmark External Programs, addresses the wider environment in which the curriculum development process is taking place. Competitive, peer, and elite programs should be surveyed and evaluated. Competitive programs are those that compete for students and whose students compete with the object program's graduates for jobs or graduate program admission. Peer programs are those that are considered similar in content, size, and quality. Elite programs are those that have outstanding reputations who we would like to be competitive with. The features and advantages that are valuable and unique from these programs should be noted and evaluated within a cost / benefit / feasibility framework.

The fourth guideline, Assess Existing Program, establishes a baseline for future change. An honest and critical assessment of the current programs strengths and weaknesses should be performed. This assessment should include requirements demanded from the university and school as well as the desired features for the program. This should also include an evaluation of the resources available to provide the curriculum delivered, e.g. faculty, labs, and software. A comparison of the current program to peer and elite programs should be performed to identify opportunities for improvement or competitive advantages. One outcome of the process should be a set of desired and a set of required changes. Again this assessment should include constituent administrators, faculty, noteworthy external reviewers, employers and students. This assessment may recognize any future available resources or identify potential untapped resources and plans to develop these.

The fifth guideline, Iterative Process, recognizes the necessity of establishing feedback loops among the steps involved in the process and the need to incorporate information gained and decisions made back into the beginning steps. As with any iterative process, care must be taken to establish some type of decision rule or determination as to when the process is complete (no infinite loops!). However, the process should include at least two discussion cycles for each phase to provide time for reflection and innovation.

The sixth guideline, Optimize Course Offerings, addresses the implementation of the program. Obviously, decisions regarding what specific courses must be offered and the requirements for majors, minors, concentrations, etc. must be made. The conclusion of the process should be to group knowledge areas and eliminate undesirable duplication. The implementation must take into account several constraints, as follows. These course offerings must be consistent with achievable faculty capabilities. They must be administratively supportable - the number of preparations for faculty must be reasonable and facilities must be available or acquirable. They must challenge and prepare students to add value to their companies, organizations or prepare for graduate education. They must provide program flexibility to allow students to achieve meeting the program requirements through prerequisites, co- 
requisites, and course sequences. The course offerings should exploit technology in the learning process e.g. computer aided learning. The course content should emphasize lifetime learning (McGrath, May 4, 2002) and should address theory and concepts and not specific technologies.

\section{The Review Process}

With the Design Guidelines in mind, we will start the review generally following the sequence provided in Diagram 2. The goal is to develop curricula that fulfill the mission of the program while effectively using team resources in minimum calendar time. The management of the process is critical to efficient progress through the review process. A respected team leader should be appointed to lead and moderate the team's sessions and assign the tasks necessary to complete the review process. Curricula review is typically initiated by the MIS chair with the support of the dean's office and the MIS faculty. The team leader is appointed and the MIS faculty starts the research phase of the review.

The objective of Phase 1 is to take advantage of the knowledge that is available in academic, industry and other professional organizations that is relevant to MIS curricula. The articles are indexed and stored in a networked data base so that they can be accessed by team members. This is an important step to the team building process and starts to build a common knowledge base for team deliberations. The index prevents duplication and the 24X7 network availability allows team members to access information at the time and location of convenience.

Phase 2 includes the formal organization of the review team and process. The review phases, schedule and ground rules are discussed and adjustments made as necessary. Agreement on these three elements is essential. Ground rules are suggested in Table 2 that experience has proved to be beneficial. It is important that team members agree to the ground rules since that is necessary to assure timely progress and eliminate repeating discussions and decisions. The ground rules/requirements provided in Table 2 are important to assure the efficient and effective completion of the review process.

Table 2: Review Process Ground Rules

A networked database must always be available to all team members

The majority opinion is accepted when a consensus can not be reached

Team sessions are limited to reaching consensus and making decisions

Individual/sub-group tasks are used for data and knowledge collection

Phase 3 starts with the selection of the competitive, peer and elite MIS programs. MIS faculty and appropriate SBA administrators should agree on the selection of the MIS programs to be studied. The selected schools are assigned to team members to be contacted, studied, summarized and posted to the database. A substantial amount of the information can be collected from web sites. Planned changes in the programs can only be identified by contacting the school. The team needs to spend some time discussing and comparing these programs, since valuable insights can be gained that will be useful during the course design phase. It is suggested that the individuals doing the study lead a brief discussion of that program.

Diagram 2: The Review Process

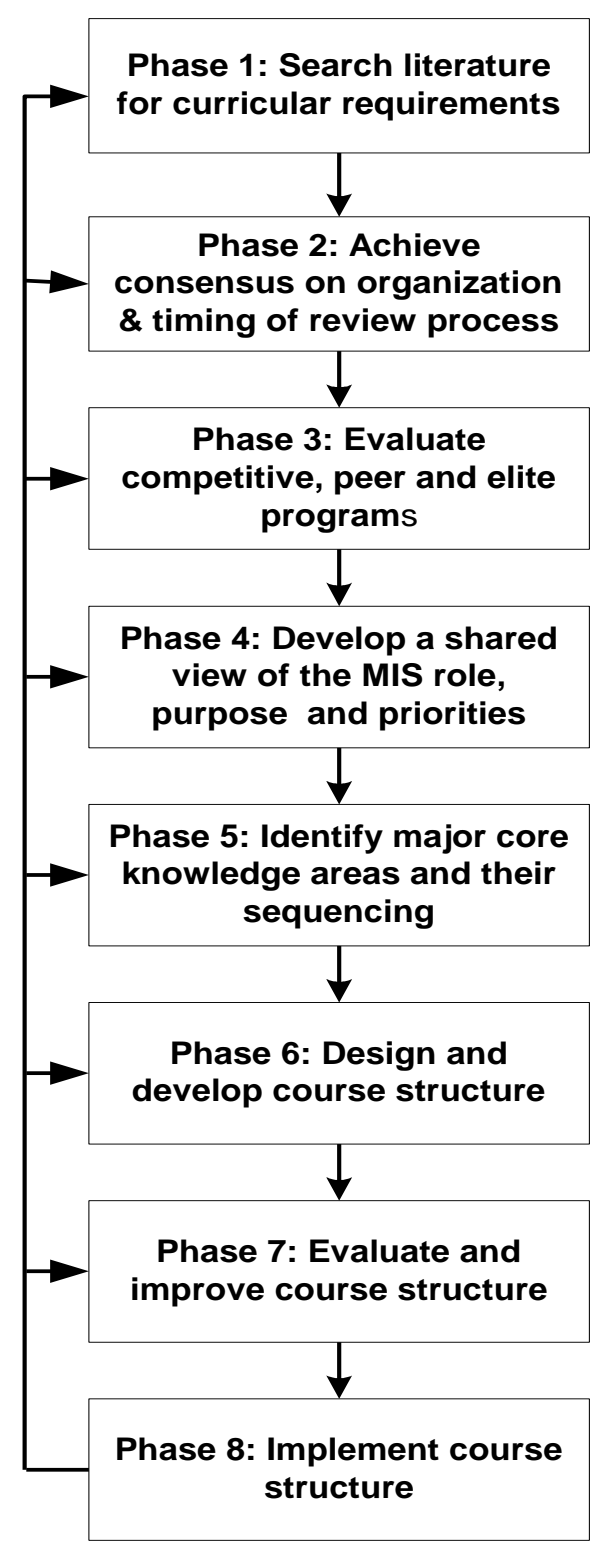


The fourth phase involves the team developing a shared view of the role of MIS role, mission, priorities and objectives. This phase is extremely important, since it involves the articulation of who you are, what you are trying to achieve, and the nature of your graduates. If you want to be world class, you are unlikely to achieve this result if it is not explicitly stated as a goal and start working to achieve it. Team consensus is not an option, it is a requirement! Mission drives the review process, the nature and allocation of resources, faculty actions and a host of other decisions. MIS priorities should be clearly established. What are the priorities with respect to majors, minors, thematic sequences and electives for other departments and students in MIS? Should the MIS area offer tracks? If so - what tracks? Should MIS participate in integrative tracks, such as supply chain, ERP, logistics or accounting ISs? What service courses should the MIS program provide to other departments? The decisions in this phase have to be supportable with existing or forthcoming faculty, student, IT and other resources. The quality of the rest of the process and the success of your program depends on taking the mission phase seriously. A well stated mission statement is also a very useful public relations tool if it is taken seriously.

Phase 5 requires the identification of major core knowledge areas and their sequencing. The initial focus is on identifying essential and desirable MIS knowledge areas. This phase uses the earlier literature and program research to assemble IT concepts into major knowledge areas. This process should not be course driven, but strive to be exhaustive in the identification of IT concepts applicable to an MIS program. The knowledge areas should be captured with work processing software and placed in the database. Technology and educational delivery ideas should also be documented with respect to knowledge areas. The availability of tutorials and computer aided delivery systems should be exploited.

Phase 6 focuses on organizing the related knowledge areas into courses, organizing the courses into sequences, and then establishing prerequisites and co-requisites. It is crucial that the course design and structure process be iterative. The ability to step back, reflect and take a fresh look at the courses and structures is invaluable. Phases 6 and 7 are deliberately separate to force a continuing rigorous design process for the courses and their structure. Toward the end of this phase, individuals should be assigned as the focal point for each course and follow it though to the approval process that occurs in the eighth phase. Changes can be directed to them making the course building process manageable and the database current. It may be useful at this point to present the curricula to a knowledgeable educator who has not been involved in the process. Interested deans, adjunct faculty, and academic advisors are often good candidates for this presentation.

Phase 7 provides the final evaluation and improvement of the course structure and sequencing. Particular focus should be on eliminating undesirable duplication and building depth and breadth of knowledge. This phase includes all of the coordination that may be required with respect to courses that service other departments as well as departments that may service MIS. At some schools, there may be cooperative relationships with computer science departments if they exist. The MIS chair must initiate appropriate actions with respect to faculty development, IT support, and changes in the infrastructure where required.

The last and $8^{\text {th }}$ phase requires compliance with internal governance procedures. The appropriate documentation must be prepared, coordinated and submitted through the approval authorities. University catalogs, college publications, departmental brochures, web sites, advising and other documents must be appropriately updated.

Similar to the system development life cycle, this process has evolved over several iterations. Using a documented, systematic process provides the capability of evaluating and improving the process during later curricular reviews as well as documenting on-going program reviews for external certification bodies. Equally important, it enables the process to proceed with greater efficiency and effectiveness. It remains a judgment as to how frequently and at what level of rigor the process needs to be repeated.

\section{Discussion And Conclusion}

Given the ever increasing pace of change in the area of information and communication technologies it is important that MIS programs, in comparison to other areas, continually assess and change its course content and 
course offerings. The process given in this paper has been successfully used at two universities to evaluate and improve the quality of the educational experience for MIS students.

\section{References}

1. ACM, AIS and AITP, IS 2002 Model Curriculum and Guidelines for Undergraduate Degree Programs in Information Systems, 2002.

2. $\quad$ Editors, "10 Emerging Technologies That Will Change the World", Technology Review, January 31, 2003.

3. Editors, "Emerging technologies that will change the world", The Technology Review, January/February 2001.

4. Hoffman, Thomas, "Job Skills: Preparing Generation Z”, ComputerWorld, Vol. 37, No. 34, August 25, 2003.

5. Mann, Joan, “IT Education's Failure to Deliver Successful Information Systems: Now is the Time to Address the IT-User Gap", Journal of Information Technology Education, Vol 1, No. 4, 2002.

6. McGrath, Dermot, "Lifelong Learning: The Goal of Top Employers", ComputerWorld, May 4, 2002, http://www.computerworld.com/departments/surveys/bestplaces/global_story/0,10992,69339,00.html.

Notes 
Notes 